\title{
Hemorrhoidal Disease, from Legacy to a Change of Perspective
}

\section{Umberto Morelli}

Department of Colorectal Surgery, State University of Campinas, Campinas, São Paulo, Brazil

Since Sir Alan Parks studies, describing pathogenesis and surgical treatment[1] of hemorrhoidal disease[2-4], the diagnosis and clinical approach of this pathological entity, has come a long way. The studies about the real cause of this common pathology got an impulse since the findings, by a Japanese group [5] of pathophysiology of hemorrhoidal artery perfusion, that lead to a new clinical and surgical approach to this clinical entity.

Anorectal disorders are a common problem that all kind of clinicians face in daily practices, from General Practitioners to Emergency doctors ending to Colorectal Surgeons. The most common of them is hemorrhoidal disease, from one side the most diagnosed (sometimes with excess from some clinician category) that attributes every perianal discomfort or bleeding to this pathological entity. A lot of scientific papers are present in literature: if you realize a simple keyword search on PUBMED", searching for "hemorrhoids", more than 5630 articles will show up as results. One pivot point is present in all articles, also the recent ones: Park's classification of hemorrhoidal disease[4].Other pathologies were object of revision and modernizations of classification criteria (just think about IBS and Rome Criteria) [6], but legacy resisted to ageing for what concerns hemorrhoidal disease.

We still classify and accordingly treat hemorrhoids using studies that were accomplished and applied circa seventy years ago, with no doubts still good results.

But there is a significant part of scientific community that started not to accept this kind of pathway, starting with the studies and the subsequent changes in surgical approach led by the Italian surgeon Longo[7] in the late nineties, which moved the entire concept of hemorrhoidectomy from a orificial point of view to a more complex, pelvic-linked pathophysiological disease. This obviously shacked the scientific community, creating debate and obviously a series os scientific researches comparing the classical excisional technique[8, 9] to the other and trying to establish a new pathway of treatment and finally define what to do and in which kind of patients. After a short period of trials, some negative point arose around the Longo technique [10-18], with this debate still in place in congresses and symposium around the word and in modern literature[16].

Some part of the colorectal surgical community decided to use the classical clinical approach, some others embraced the new idea and started to treat all patients with the new technique. But everyone continued to use the traditional Park's approach to classification of hemorrhoidal disease. Some scientific societies started again to look inside the classifications, posing to the scientific community the question about the opportunity to revise the Park's approach[19], at the beginning with fierce resistance from the academic community.

Then again, something new started to arise. New studies about physiology published by Morinaga in 1995, at the beginning ignored by great part of surgical community, but with the merit of switching attention form the technical approach to the physiological cause of hemorrhoidal disease and its evolution: vascularization. After more or less 10 years and the development of surgical devices that are dedicated

\section{Publication History:}

Received: December 21, 2014

Accepted: February 08, 2015

Published: February 10, 2015

\section{Keywords: \\ Anorectal disorders, Hemorrhoidal disease}

to operate with a standard technique, the Transanal Hemorrhoidal Desarterialization stepped up as a new and minimally invasive approach for the treatment of hemorroids[20-28].

Again, some authors are still debating if this is the correct approach, with new studies[29] and verifying the efficacy and feasibility of this relatively new surgical approach.

Again, Sir Alan Parks classification is still in place, after 70 years, defining clinical and surgical options. As I said in the previous paragraph, if a technique is so superior to others, why the flourishing of new technical approaches in a so (relatively) smaller time? Is there something we,as scientific community, are missing? Maybe the way we look to and classify this disease?

Some colleagues are trying to change perspective. A new concept in hemorrhoids surgery is taking place, that hemorrhoidal disease is not a "symmetrical" clinical problem, both for symptoms both from an anatomical point of view. Patients can have a III degree (according to Parks' classification) nodule associated to a II-degree one and an internal mucosal prolapse, not affecting the hemorrhoidal tissue at all in terms of volume on one side, all in one patient. Do we use a "one -size-fits-all" therapeutic approach as we do today, with failure rates still statistically significant, or it is time to propose a more "tailored" approach to this common pathology[30]?

Is it time to change perspective, so to change clinical and mainly surgical approach?

Arezzo in this paper from 2011 states that "Societies' guidelines recommend a tailored surgery, i.e., the use of different procedures according to the grade of hemorrhoids, which suggests that patients should be operated by a specialist colorectal surgeon, able to perform different surgeries and to deal with complications and failures"[31].

The path is still long and full of doubts, and we as scientific community, must keep the debate and experimentation alive, as well as our mind open to new perspectives, running away from dogmas.

"Corresponding Author: Dr. Umberto Morelli, Department of Colorectal Surgery, State University of Campinas, Campinas, São Paulo, 13083-970, Brazil; E-mail: umorelli@gmail.com

Citation: Morelli U (2015) Hemorrhoidal Disease, from Legacy to a Change of Perspective. Int J Gastroenterol Disord Ther 2: 112. doi: http://dx.doi. org/10.15344/2393-8498/2015/112

Copyright: () 2015 Morelli. This is an open-access article distributed under the terms of the Creative Commons Attribution License, which permits unrestricted use, distribution, and reproduction in any medium, provided the original author and source are credited. 
Citation: Morelli U (2015) Hemorrhoidal Disease, from Legacy to a Change of Perspective. Int J Gastroenterol Disord Ther 2: 112. doi: http://dx.doi. org/10.15344/2393-8498/2015/112

\section{References}

1. PARKS AG (1959) Submucous haemorrhoidectomy. Proc R Soc Med 52: 89-91.

2. PARKS AG (1955) De haemorrhois; a study in surgical history. Guys Hosp Rep 104: 135-156.

3. PARKS AG (1958) Modern concepts of the anatomy of the ano-rectal region. Postgrad Med J 34: 360-366.

4. PARKS AG (1962) Haemorrhoids. Practitioner 189: 309-316.

5. Morinaga K, Hasuda K, Ikeda T (1995) A novel therapy for interna hemorrhoids: ligation of the hemorrhoidal artery with a newly devised instrument (Moricorn) in conjunction with a Doppler flowmeter. Am J Gastroenterol 90: 610-613.

6. Shih DQ, Kwan LY (2007) All Roads Lead to Rome: Update on Rome II Criteria and New Treatment Options. Gastroenterol Rep 1: 56-65.

7. Longo A (2002) Stapled anopexy and stapled hemorrhoidectomy: two opposite concepts and procedures. Dis Colon Rectum 45: 571-572.

8. Thaha MA, Campbell KL, Kazmi SA, Irvine LA, Khalil A, et al. (2009) Prospective randomised multi-centre trial comparing the clinical efficacy, safety and patient acceptability of circular stapled anopexy with closed diathermy haemorrhoidectomy. Gut 58: 668-678.

9. Thaha MA, Irvine LA, Steele RJ, Campbell KL (2005) Postdefaecation pain syndrome after circular stapled anopexy is abolished by oral nifedipine. $\mathrm{Br}$ J Surg 92: 208-210.

10. Sultan S (2014) Longo procedure (Stapled hemorrhoidopexy): Indications, results. J Visc Surg.

11. Tokunaga $Y$, Sasaki H, Saito $T$ (2010) Evaluation of sclerotherapy with a new sclerosing agent and stapled hemorrhoidopexy for prolapsing internal hemorrhoids: retrospective comparison with hemorrhoidectomy. Dig Surg 27: 469-472.

12. Uras C, Baca B, Boler DE (2008) Circular stapled hemorrhoidopexy: experience of a single center with 445 cases. World J Surg 32: 1783-1788.

13. Williams R, Kondylis L, Geisler D, Kondylis P (2007) Stapled hemorrhoidopexy height as outcome indicator. Am J Surg 193: 336-339.

14. Wong JC, Chung CC, Yau KK, Cheung HY, Wong DC, et al. (2008) Stapled technique for acute thrombosed hemorrhoids: a randomized, controlled trial with long-term results. Dis Colon Rectum 51: 397-403.

15. Wong LY, Jiang JK, Chang SC, Lin JK (2003) Rectal perforation: a lifethreatening complication of stapled hemorrhoidectomy: report of a case. Dis Colon Rectum 46: 116-117.

16. Yang J, Cui PJ, Han HZ, Tong DN (2013) Meta-analysis of stapled hemorrhoidopexy vs LigaSure hemorrhoidectomy. World J Gastroenterol 19: 4799-4807.

17. Zanella S, Spirch S, Scarpa M, Ricci F, Lumachi F2 (2014) Long-term outcome of stapled transanal rectal resection (STARR) versus stapled hemorrhoidopexys (STH) for grade III-IV hemorrhoids: preliminary results. In Vivo 28: 1171-1174.

18. Zaragozá C, García Fadrique A, Castaño S, Villalba R, Bruna Esteban M, et al. (2007) [Results of Longo's stapled hemorrhoidectomy in ambulatory surgery for grade III-IV hemorrhoids]. Cir Esp 81: 130-133.

19. Gaj F, Trecca A, Busotti A, Brugiotti C, Carboni M (2002) The new classification of hemorrhoids: PATE 2000-Sorrento. History of the scientific debate. Minerva Chir 57: 331-339.

20. Festen S, van Hoogstraten MJ, van Geloven AA, Gerhards MF (2009) Treatment of grade III and IV haemorrhoidal disease with PPH or THD. A randomized trial on postoperative complications and short-term results. Int J Colorectal Dis 24: 1401-1405.

21. Infantino A (2010) Transanal haemorrhoidal artery echodoppler ligation and anopexy (THD) is effective for II and III degree haemorrhoids. A prospective multicentre study. Colorectal Dis 12: 1274.

22. Teo JY, Kam MH, Eu KW (2010) Letter to the editor on the article "Treatment of grade III and IV haemorrhoidal disease with PPH or THD. A randomized trial on postoperative complications and short-term results". Int J Colorectal Dis 25: 1385
23. Ratto C, Giordano P, Donisi L, Parello A, Litta F, et al. (2011) Transanal haemorrhoidal dearterialization (THD) for selected fourth-degree haemorrhoids. Tech Coloproctol 15: 191-197.

24. Sobrado-Junior CW, Hora JA (2012) Transanal desarterialization guided by Doppler associated to anorectal repair in hemorrhoids: THD technic. Arq Bras Cir Dig 25: 293-297.

25. Verre L, Rossi R, Gaggelli I, Di Bella C, Tirone A, et al. (2013) PPH versus THD: a comparison of two techniques for III and IV degree haemorrhoids. Personal experience. Minerva Chir 68: 543-550.

26. Galati G, De Vincentis A, Ripetti V, La Vaccara V, Vespasiani-Gentilucci U, et al. (2014) Haemorrhoidal disease in severe portal hypertension: a combined approach with transjugular intrahepatic portosystemic shunt (TIPS) and transanal haemorrhoidal dearterialization (THD). Arch Med Sci 10: 195-196.

27. Ratto C (2014) THD Doppler procedure for hemorrhoids: the surgical technique. Tech Coloproctol 18: 291-298.

28. Ratto C, Parello A, Veronese E, Cudazzo E, D'Agostino E, et al. (2015) Doppler-guided transanal haemorrhoidal dearterialization for haemorrhoids: results from a multicentre trial. Colorectal Dis 17: 010-19.

29. Giordano P, Tomasi I, Pascariello A, Mills E, Elahi S (2014) Transanal dearterialization with targeted mucopexy is effective for advanced haemorrhoids. Colorectal Dis 16: 373-376.

30. Elbetti C, Giani I, Consiglio FM, Novelli E, Santini A, et al. (2014) Tailored excisional treatment for high-grade haemorrhoidal disease. Updates Surg 66: 283-287.

31. Arezzo A, Podzemny V, Pescatori M (2011) Surgical management of hemorrhoids. State of the art. Ann Ital Chir 82: 163-172. 